\title{
Author Correction: Crossover between the adiabatic and nonadiabatic electron transfer limits in the Landau-Zener model
}

\author{
Guang Yuan Zhu, Yi Qin, Miao Meng (1), Suman Mallick, Hang Gao, Xiaoli Chen, Tao Cheng, Ying Ning Tan, \\ Xuan Xiao, Mei Juan Han, Mei Fang Sun \& Chun Y. Liu (D)
}

Correction to: Nature Communications https://doi.org/10.1038/s41467-020-20557-7, published online 19 January 2021.

The original version of this Article contained an error in the equation in the first paragraph of the Introduction, which incorrectly read 'adiabatic : $v_{\mathrm{el}}>>v_{\mathrm{n}}$; nonadiabatic $: v_{\mathrm{el}}<<n_{\mathrm{n}}$ '. The correct version states 'nonadiabatic : $v_{\mathrm{el}}<<v_{\mathrm{n}}$ ' in place of 'nonadiabatic: $v_{\mathrm{el}}<<n_{\mathrm{n}}$ '.

The original version of this Article also contained an error in the first sentence of the first paragraph of the 'Synthesis and characterization of the mixed-valence $\mathrm{Mo}_{2}$ dimers' section of the Results, which incorrectly read ' $4,4^{\prime}-\left(\mathrm{EE}^{\prime} \mathrm{C}\left(\mathrm{C}_{6} \mathrm{H}_{4} \mathrm{C}\right)_{3} \mathrm{EE}^{\prime}\right)^{2-}$. The correct version states ' $4,4^{\prime}-\left(\mathrm{EE}^{\prime} \mathrm{C}\left(\mathrm{C}_{6} \mathrm{H}_{4}\right)_{3} \mathrm{C} \mathrm{EE}^{\prime}\right)^{2-}$ ' in place of ' $4,4^{\prime}-\left(\mathrm{EE}^{\prime} \mathrm{C}\left(\mathrm{C}_{6} \mathrm{H}_{4} \mathrm{C}\right)_{3} \mathrm{EE}^{\prime}\right)^{2-}$.

The original version of this Article also contained an error in the fifth sentence of the first paragraph of the 'Optical behaviors of the mixedvalence complexes' section of the Results, which incorrectly read ' $\left[\mathrm{OO}-(\mathrm{ph})_{3}-\mathrm{OO}\right]^{\prime}$. The correct version states ' $\left[\mathrm{OO}-(\mathrm{ph})_{3}-\mathrm{OO}\right]^{+}$' in place of ' $\left[\mathrm{OO}-(\mathrm{ph})_{3}-\mathrm{OO}\right]$ '.

The original version of this Article also contained an error in the legend title of Fig. 3, which incorrectly read 'Schematic description of donor-acceptor electron in the phenylene bridged $\mathrm{Mo}_{2}$ dimer'. The correct version adds 'transfer' after 'donor-acceptor electron'.

The original version of this Article also contained an error in the first sentence of the third paragraph of the Discussion, which incorrectly read ' $\Delta G \gg 2 H_{\mathrm{ab}}$ '. The correct version states ' $\Delta G^{*} \gg 2 H_{\mathrm{ab}}$ ' in place of ' $\Delta G \gg 2 H_{\mathrm{ab}}$ '.

These have now been corrected in the PDF and HTML versions of the Article.

Published online: 15 February 2021

\footnotetext{
(c) Open Access This article is licensed under a Creative Commons Attribution 4.0 International License, which permits use, sharing, adaptation, distribution and reproduction in any medium or format, as long as you give appropriate credit to the original author(s) and the source, provide a link to the Creative Commons license, and indicate if changes were made. The images or other third party material in this article are included in the article's Creative Commons license, unless indicated otherwise in a credit line to the material. If material is not included in the article's Creative Commons license and your intended use is not permitted by statutory regulation or exceeds the permitted use, you will need to obtain permission directly from the copyright holder. To view a copy of this license, visit http://creativecommons.org/licenses/by/4.0/.
}

(C) The Author(s) 2021 